\title{
PRODUÇÃO DE MATÉRIA SECA DE DIFERENTES ESPÉCIES FORRAGEIRAS DE INVERNO, EM ÁREAS DEGRADADAS
}

\author{
Dry Matter Production of Different Winter Forage Species, \\ in Degraded Areas
}

\author{
Davi André Martins Claro ${ }^{1}$ \\ Flora Osaki ${ }^{2}$
}

\section{Resumo}

Com o objetivo de identificar espécies forrageiras de inverno que se adaptem a áreas degradadas e determinar o teor de $\mathrm{N}$ nas plantas, foi realizado um ensaio em Campestre, São José dos Pinhais/PR, no período de junho a outubro, 2001. O delineamento estatístico utilizado foi o de blocos ao acaso com 5 tratamentos e 4 repetições. Os tratamentos contaram com 5 espécies forrageiras: aveia preta, aveia branca, centeio, ervilhaca e azevém. O preparo do solo constou de aração e gradagem, aplicação de calcário 30 dias antes da semeadura e adubação de base com $500 \mathrm{~kg}$ de adubo na formulação $4-14-8$. Foram adicionados ainda $2,00 \mathrm{~kg} / \mathrm{m}^{2} \mathrm{de}$ adubo orgânico (estrume bovino e suíno e cama de aves). A semeadura foi feita a lanço e os cortes aos 64 , 84 e 104 dias após a emergência. Os dados obtidos foram submetidos à análise de variância e aqueles que se mostraram homogêneos comparados pelo Teste de Tukey ao nível de $5 \%$. Os resultados mostraram que não houve diferenças estatísticas entre os tratamentos no primeiro e terceiro corte para a produção de matéria seca e teor de nitrogênio. No segundo corte, as maiores produções de matéria seca foram obtidos para 0 centeio, aveia preta e ervilhaca, com $5.235 \mathrm{~kg} / \mathrm{ha}, 4.982 \mathrm{~kg} / \mathrm{ha}$ e $3.893 \mathrm{~kg} / \mathrm{ha}$, respectivamente, e não diferiram estatisticamente entre si. Os teores mais elevados de nitrogênio, para o segundo corte foram verificados para a ervilhaca, o centeio e a aveia preta que não apresentaram diferenças estatísticas entre si, 157,9 kg/ ha 131,4 $\mathrm{kg} / \mathrm{ha}$ e $107,9 \mathrm{~kg} / \mathrm{ha}$, respectivamente.

Palavras-chave: Ervilhaca; Azevém; Centeio; Aveia preta; Aveia branca; Produção de matéria seca; Nitrogênio.

\footnotetext{
Aluno de Graduação de Engenharia Agronômica PUCPR

2 Centro de Ciências Agrárias e Ambientais, Profa./PUCPR

e-mail: rk_osaki@netpar.com.br
} 


\section{Abstract}

The objectives of this work were to identify winter forage species capable of adapting to degraded areas and to determine the contents of $\mathrm{N}$ in the plants. The work was conducted in Campestre, São José dos Pinhais/ PR from June to October, 2001. A complete randomized block design with 5 treatments and 4 replicates was used. The five treatments were the forage species: black oats, white oats, rye, vetch (Vicia sativa) and rye grass. The soil was prepared through plowing, gradation and application of lime 30 days before sowing and fertilization based on $500 \mathrm{~kg}$ of the formulae $4: 14: 8$. Additionally, $2.00 \mathrm{~kg} / \mathrm{m}^{2}$ of organic fertilizer (bovine, swine and poultry manure) were applied. The sowing was made by hand and the cuts were made at 64,84 and 104 days after germination. The data were submitted to analyses of variance and those that were not homogeneous were compared by the Tukey test at the $5 \%$ level of probability. The results showed no statistical differences among treatments in the first and third cuts for dry matter production and $\mathrm{N}$ content. In the second cut, greatest dry matter productions were obtained for rye, black oats and vetch, with 5,235 $\mathrm{kg} / \mathrm{ha}, 4,982 \mathrm{~kg} / \mathrm{ha}$ and 3,893 kg/ha, respectively, with no statistical differences among them. The highest $\mathrm{N}$ contents for the second cut were yielded by vetch, rye and black oats, with no statistical differences among them, with, $157.9 \mathrm{~kg} / \mathrm{ha}, 131.4 \mathrm{~kg} / \mathrm{ha}$ and $107,9 \mathrm{~kg} / \mathrm{ha}$, respectively.

Keywords: Vetch; Rye Grass; Rye; Black oats; White oats; Dry matter production; Nitrogen.

\section{Introdução}

A preocupação atual em manter os recursos naturais, como o solo e o ambiente em que se vive, tem colocado em destaque a recuperação de solos improdutivos resultantes da atividade antrópica. A análise das ações empreendidas mostra que a degradação, seja por erosão, desgaste pela falta ou excesso de nutrientes, exportação ou poluição, tem tornado os solos que outrora eram agricultáveis em áreas inaptas fora de suas reais aptidões. É o caso de terrenos receptores de entulhos, como latas de refrigerantes, pedras, resíduos de construções/ferro, concreto e plástico, de forma irracional e descontrolada, transformados em verdadeiros lixões. As medidas adotadas para a recuperação destas áreas muitas vezes são ineficientes, pois se utilizam de técnicas e procedimentos testados e aprovados em outros ambientes, nos quais foram eficientes, mas cuja aplicação destina-se a situações distintas e por isso não trazem os resultados desejados (SEITZ, 1989).

Assim, dependendo do grau de degradação do meio ambiente, técnicas simples podem ser utilizadas para a sua recuperação, dispensando tratamentos dispendiosos. A implantação de forrageiras em áreas degradadas, desde que observadas algumas condicionantes básicas, é uma alternativa para promover a reabilitação do solo. A pastagem cultivada é um dos procedimentos mais econômicos para recuperar áreas. São raras no Brasil as áreas degradadas irrecuperáveis, quando se adota um manejo adequado. O que varia é o tempo necessário para que o solo se dinamize e este tempo está intimamente relacionado com 0 grau de degradação. Portanto, antes de se iniciar qualquer processo de recuperação de áreas, é necessário avaliar as causas de degradação e o grau de comprometimento do solo e do ambiente natural (SEITZ, 1989).

A degradação das condições bióticas e abióticas provocam a médio prazo a degradação física do solo, alterando sua capacidade de retenção de água, permeabilidade e porosidade.

A degradação química do meio ambiente pode também ser a partir de fontes emissoras de poluentes. Embora mais localizadas, as áreas assim comprometidas também apresentam distintos graus de degradação. A sobrecarga química que 0 solo recebe atinge a vegetação, além de contaminar o solo. Apenas em casos isolados foram observadas contaminações irreversíveis. Já os depósitos de ferro são resultantes da deposição de obras civis ou depósitos de lixo (BAGGIO, 1992).

A recuperação de áreas degradadas é efetivamente concretizada quando as espécies selecionadas apresentam características especiais, ou seja, rusticidade, capacidade de absorção de nutrientes, água e tolerância às condições de pequena permeabilidade e drenagem inadequada.

Diversos estudos confirmam que as plantas forrageiras são eficientes na conservação e recuperação de solos degradados (OSAKI; TRAAD DA SILVA, 2000). Além disso, é significativa a sua eficiência em fornecer nitrogênio (leguminosas), reciclar outros nutrientes e aumentar o teor de matéria orgânica, quando comparadas com cultivos anuais continuados (THOMAS, 1975).

O solo exerce influência fundamental sobre a distribuição e o crescimento das plantas forra- 
geiras. Sendo assim, deve-se examinar o solo e sua fertilidade atual, conhecer o comportamento dos elementos nutricionais que o compõem, suas oscilações, intensidade e distribuição durante o ano, a fim de assegurar que apresente boas condições para o crescimento da planta forrageira.

Entre todos os nutrientes vegetais, o nitrogênio $(\mathrm{N})$ se destaca por ser o elemento de maior demanda pela planta forrageira, pois faz parte da estrutura química de dois de seus constituintes principais: proteínas e ácidos nucleicos, além de participar dos processos de absorção iônica, fotossíntese, respiração, síntese, multiplicação e diferenciação celulares. Também é integrante de enzimas e hormônios (LAWLOR et al.,1988).

Entretanto, não basta associar a produção apenas ao nitrogênio, é necessário também associá-la a outras adubações e suas formas de utilização (OSAKI; TRAAD DA SILVA, 2000).

O solo, em conjunto com outros fatores, é um dos principais responsáveis pela abundância e qualidade das forragens. Nada adiantaria o plantio ou semeadura de espécies geneticamente melhorada com raízes profundas em solos rasos e degradados, ou de espécies exigentes em umidade em solos sujeitos a longas estiagens e/ou encharcamentos. Torna-se fundamental o conhecimento do período de estiagem e da precipitação total anual, além da sua distribuição, de oscilações bruscas na temperatura, nebulosidade e radiação média recebida, número de dias com geadas, entre outros, para evitar possíveis estresses na cultura (CORREA, 1996).

A baixa produtividade em áreas degradadas é conseqüência da deficiência nutricional, que compromete a estabilidade da produção agropecuária. Assim, a qualidade da forragem reflete, entre outros fatores, as condições de fertilidade do solo (OLIVEIRA et al., 1998). Deve-se explorar sua viabilidade assegurando que as plantas terão os nutrientes necessários fornecidos por meio da adubação, seja orgânica ou inorgânica, contribuindo significativamente no processo produtivo. É necessário, portanto, uma minuciosa análise do comportamento solo/clima/planta, para a correta escolha do tipo de exploração e seleção das plantas forrageiras a serem cultivadas nessas áreas.

Entre as espécies de maior interesse estão a aveia branca, o azevém, o centeio e a ervilhaca.
A aveia é um cereal originário da Ásia antiga. Desta região passou para a Europa, cujas condições de solo e clima permitiram expansão da cultura, tornando-se importante fonte para alimentação humana e animal (FLOSS, 1982). As aveias podem ser perenes ou anuais. No entanto, as cultivadas são anuais, sendo as mais importantes a Avena sativa (branca) e a Avena strigosa Schreb (preta). O ciclo é variável, em torno de 3 a 5 meses. São espécies de estação fria, porém apresentam cultivares adaptadas a regiões de climas mais quentes. No Paraná, pode ser cultivada em todas as regiões, apenas não tolerando aquelas excessivamente úmidas, onde é intenso 0 ataque de ferrugem. Produz bem em quase todos os tipos de solos, vegetando melhor naqueles com bom teor de matéria orgânica, permeáveis, drenados e férteis (MONTEIRO et al., 1996).

Dentre as opções forrageiras para a estação fria, a aveia é uma das espécies que apresenta maior potencial para produção de forragem neste período, contribuindo significativamente para a produção na região Sul do Brasil. Em condições de média fertilidade, na região de Ponta Grossa, 0 rendimento total de matéria seca submetida a cortes no estádio vegetativo superou $5 \mathrm{t} /$ ha durante a estação de crescimento.

O azevém - Lolium multiflorum Lam é originário da região mediterrânea (Europa, Ásia, Norte da África). É uma gramínea anual, rústica e agressiva que produz muitos perfilhos.

$\mathrm{O}$ azevém é adaptado a temperaturas baixas, solos férteis, mas pode proporcionar produções relativamente altas, em solos bem manejados, úmidos, argilosos e com bom teor de matéria orgânica, resistindo bem à umidade excessiva e à acidez do solo.

0 rendimento é de 7 a 9 t de matéria seca/ha/ ano ou 40 a 50 t de matéria verde/ha/ ano (MONTEIRO et al., 1996).

O centeio - Secale cereale L é um cereal originário da Ásia Central, de polinização cruzada apresentando acentuada variabilidade genética. É uma espécie anual, rústica, que suporta condições adversas de clima e solo, com boa eficiência na absorção de nutrientes. Produz muita massa, é agressivo, com sistema radicular profundo, sendo recomendado para recuperação de solos degradados. Apresenta ciclo de produção mais reduzido que a aveia e o azevém, porém, em geral é mais precoce, produzindo forragem mais cedo do que estas espécies (MONTEIRO et al., 1996). 
O centeio é tolerante à presença de alumínio, entretanto, é recomendável eliminá-lo do solo para um melhor aproveitamento do fósforo. Em razão da precocidade e facilidade de implantação, mesmo sob condições adversas de clima, o centeio tem sido uma das opções forrageiras para o período de inverno nas regiões sujeitas a temperaturas baixas nos Estados do Sul do país (MONTEIRO et al., 1996).

A ervilhaca - Vicia spp originária da Europa, Ásia e África, foi introduzida provavelmente pelos primeiros colonos italianos do Sul do país. A ervilhaca é uma leguminosa forrageira anual de excelente qualidade e com bom desenvolvimento em temperaturas amenas. É uma planta autógama e também de fecundação cruzada (alogamia).

É mais tolerante a solos ácidos que a maioria das outras espécies de leguminosas de inverno. Responde, no entanto, à melhoria da fertilidade com maiores produções de forragem. Suporta a seca prolongada e é suscetível ao encharcamento do solo (MONTEIRO et al., 1996).

O ciclo vegetativo da ervilhaca é de 150 a 200 dias, com produtividade de 300 a $800 \mathrm{~kg} / \mathrm{ha}$. Ocorre deiscência natural das vagens maduras e as sementes caem ao solo no final do ciclo, vindo a germinar posteriormente, em condições favoráveis, no início do inverno (MONTEIRO et al., 1996). Essa espécie apresenta excelente efeito residual no solo, melhorando suas propriedades. Promove aumento no rendimento de vários cultivos, dentre os quais se destaca o milho. Suporta vários cortes ou pastejos (MONTEIRO et al., 1996).

Em experimento com ervilhaca peluda em latossolo roxo álico com elevada acidez e baixo teor de fósforo, conduzido na localidade de Mangueirinha (Sudoeste do Paraná), foi alcançada produção de 15 t/ha de massa verde (4,93 t de MS/ ha), comprovando a rusticidade e o bom rendimento desta espécie em condições adversas (MONTEIRO et al. 1996). Em solo mais fértil, localizado na Fazenda Experimental de Ibiporã (Norte do Paraná), foram avaliadas 19 cultivares de ervilhaca (peluda e comum) semeadas em início de abril e colhidas em final de agosto, revelando rendimentos de matéria seca variando de 1,7 a 5,0 t/ ha e proteína bruta de 18,24\% a 27,38\% (SÁ, 1984).
O trabalho visa a estudar a produção de matéria seca de aveia branca e preta, azevém, centeio e ervilhaca, forrageiras de clima frio, já que é o período crítico na oferta de alimentos para a pecuária e determinar qual destas espécies terá maior aptidão para sobrepujar as dificuldades encontradas em uma área degradada, relativas aos solos e às condições climáticas adversas.

\section{Material e métodos}

O experimento foi conduzido a campo, na propriedade localizada em Campestre, município de São José dos Pinhais - Paraná, a 15 km do centro da cidade, e próximo a Serra do Mar, entre as coordenadas de $25^{\circ} 25^{\prime}$ de latitude Sul, $49^{\circ} 10^{\prime}$ de longitude Oeste e altitude média de 925 metros.

O solo é caracterizado como indefinido, conseqüência de sua degradação, fase campo subtropical e relevo com declive de 20\% (BISCAIA; OSAKI, 1989; OSAKI; BISCAIA, 1989). As amostras de solo para análise química foram coletadas das camadas de $0-20 \mathrm{~cm}$ de profundidade. Os resultados da análise do solo apresentaram os seguintes valores: $\mathrm{pH} \mathrm{CaCl} 24.31, \mathrm{H}+\mathrm{Al} 7,2 \mathrm{cmol}_{c} / \mathrm{dm}^{3} ; \mathrm{Al}$ $1,30 \mathrm{cmol} / \mathrm{dm}^{3} ; \mathrm{Ca}+\mathrm{Mg} 4,50 \mathrm{cmol}_{/} / \mathrm{dm}^{3} ; \mathrm{Ca} 3,07$ $\mathrm{cmol} / \mathrm{dm}^{3} ; \mathrm{K} 0,19 \mathrm{cmol}_{c} / \mathrm{dm}^{3} ; \mathrm{P} 11,70 \mathrm{mg} / \mathrm{dm}^{3} ; \mathrm{C}$ 18,56 g/ $\mathrm{dm}^{3}$; matéria orgânica 35,69\% e V\% 39,46.

A região, segundo a classificação de Köeppen (IAPAR, 1994), apresenta clima Cfb subtropical úmido, mesotérmico, verões frescos, geadas severas demasiadamente freqüentes, sem a estação seca, temperaturas médias máxima de $24^{\circ} \mathrm{C}$, precipitação anual de $1.500 \mathrm{~mm}$ e umidade relativa do ar com média anual de $80 \%$.

O delineamento experimental foi o de blocos ao acaso com cinco tratamentos e quatro repetições. Os cinco tratamentos testados foram aveia preta, aveia branca, centeio, ervilhaca e azevém (QUADRO 1). As variáveis avaliadas foram a produção de matéria seca $(\mathrm{kg} / \mathrm{ha})$, teor de nitrogênio (kg/ha). Cada parcela possuía dimensões de 2,0 m x 3,00 m, totalizando uma área de 6,0 m², espaçamento entre as parcelas de 0,50 m, além da bordadura, sendo a área total do experimento de $200 \mathrm{~m}^{2}$. 


\section{QUADRO 1 - Descrição dos tratamentos utilizados no ensaio}

Chart 1 - Description of the treatments used in the assay

TRAT AMENTOS

T1 AVEIA PRETA (Avena strigosa Schreb)

T2 AVEIA BRANCA (Avena sativa L.)

T3 CENTEIO (Cecale cereale L.)

T4 ERVILHACA (Vicia spp)

T5 AZEVEM (Lolium multiflorum Lam.)

Os resultados das avaliações foram submetidos à análise de variância, utilizando-se o programa SANEST - Sistema de Análise Estatística. As variáveis, cujas variâncias se mostraram homogêneas pelo teste de Bartlet, tiveram os tratamentos analisados pormeio do teste de $\mathrm{F}$ e os tratamentos significativos tiveram suas médias comparadas pelo teste de Tukey, ao nível de 5\% de probabilidade (STEEL; TORRE, 1960).

$O$ ensaio foi conduzido utilizando-se cinco espécies forrageiras, de acordo com a Quadro 1.

O preparo do solo constou de uma aração e uma gradagem. O calcário calcítico foi aplicado na quantidade de 1,5 t/ha a lanço e incorporado ao solo com enxada. Na adubação de base foi aplicado 500 $\mathrm{kg} / \mathrm{ha}$ de adubo da fórmula 4-14-8, ou seja, $150 \mathrm{~g} /$ parcela. A adubação foi aplicada a lanço manualmente e também incorporada com enxada. Foram aplicados $2,0 \mathrm{~kg} / \mathrm{m}^{2}$ da mistura de estrume bovino, suíno e cama de aves. As sementes usadas apresentaram valores culturais entre 60 a $70 \%$ (de acordo com o fomecedor). A semeadura foi feita em 06 de junho de 2001, manualmente e empregando-se $35 \mathrm{~kg} /$ ha de azevém, $95 \mathrm{~kg} / \mathrm{ha}$ de centeio, $60 \mathrm{~kg} / \mathrm{ha}$ de ervilhaca, $50 \mathrm{~kg} / \mathrm{ha}$ de aveia preta e $70 \mathrm{~kg} /$ ha de aveia branca (MONTEIRO et al., 1996). Em cada parcela foram coletadas todas as plantas de uma área de $0,25 \mathrm{~m}^{2}$ e os cortes foram realizados aos 64, 84 e 104 dias após a emergência das plantas. $O$ corte das plantas foi a $0,05 \mathrm{~m}$ acima do nível do solo, colocando-se o material colhido em pacotes de papel, os quais foram levados para o laboratónio, onde os procedimentos foram: após pesar o material verde, estas amostras foram colocadas numa estufa e secadas a uma temperatura de $60^{\circ} \mathrm{C}$, durante 72 horas e depois colocadas na mufla durante 4 horas.
Para análise do tecido vegetal, o material seco foi moído e pesado e realizada a determinação do nitrogênio pelo método de Kjeldhal (semimicro), segundo a A.O.A.C. (1965).

\section{Resultados e Discussão}

\section{Matéria Seca e Teor de Nitrogênio}

Os valores médios da produção de matéria seca e teor de nitrogênio em três épocas de corte são apresentados na Tabela 1.

Os resultados obtidos demonstraram que não houve diferença estatística na produção de matéria seca e no teor de nitrogênio no primeiro corte (TABELA 1).

Para o segundo corte obteve-se maior produtividade de matéria seca para o centeio, que foi estatisticamente diferente das produções obtidas com aveia branca e azevém. O teor de nitrogênio foi maior para a ervilhaca, centeio e aveia preta que não diferiram significativamente entre si.

Para o terceiro corte não foram verificadas diferenças significativas para a produção de matéria seca e para o teor de nitrogênio nas espécies estudadas. No segundo corte, houve acentuado acumulo de matéria seca, o que poderia sugerir um esgotamento do solo e aumento na competição intra-espécie e a senescência natural, resultando no declínio da matéria seca no terceiro corte.

A época de semeadura pode também ter causado maior rapidez no processo de desenvolvimento das espécies estudadas. 


\section{TABELA 1 - Comparação de médias de produção de matéria seca e teor de nitrogênio em três épocas de corte para plantas de aveia preta, aveia branca, centeio, ervilhaca e azevém.} Campestre, São José dos Pinhais - PR, 2001.

Table 1 - Comparison of averages of production of dry substance and nitrogen text at three times of cut for plants of black oats, white oats, rye, vetch and rye grass Campestre, São José dos Pinhais - PR, 2001

\begin{tabular}{lcccccc}
\hline Tratamento & \multicolumn{2}{c}{$1^{\circ}$ corte } & \multicolumn{2}{c}{$2^{\circ}$ corte } & \multicolumn{2}{c}{$3^{\circ}$ corte } \\
s & $\begin{array}{c}\text { Peso seco teor de N } \\
\mathrm{kg} / \mathrm{ha} \\
\mathrm{kg} / \mathrm{ha}\end{array}$ & $\begin{array}{c}\text { Peso seco } \\
\mathrm{kg} / \mathrm{ha}\end{array}$ & $\begin{array}{c}\text { teor de N } \\
\mathrm{kg} / \mathrm{ha}\end{array}$ & $\begin{array}{c}\text { Peso seco } \\
\mathrm{kg} / \mathrm{ha}\end{array}$ & $\begin{array}{c}\text { teor de } \\
\mathrm{N} \\
\mathrm{kg} / \mathrm{ha}\end{array}$ \\
\hline $\begin{array}{c}\text { Aveia Preta } \\
\text { Aveia }\end{array}$ & $1.763,66 \mathbf{a}$ & $39,05 \mathbf{a}$ & $4.982,16 \mathbf{a}$ & $107,94 \mathbf{a b}$ & $4.561,83 \mathbf{a}$ & $84,15 \mathbf{a}$ \\
Branca & $1.211,83 \mathbf{a}$ & $24,97 \mathbf{a}$ & $2.283,33 \mathbf{b}$ & $62,10 \mathbf{b c}$ & $2.808,50 \mathbf{a}$ & $113,46 \mathbf{a}$ \\
Centeio & $2.010,66 \mathbf{a}$ & $56,58 \mathbf{a}$ & $5.235,16 \mathbf{a}$ & $131,43 \mathbf{a}$ & $4.318,66 \mathbf{a}$ & $77,18 \mathbf{a}$ \\
Ervilhaca & $1.824,16 \mathbf{a}$ & $73,28 \mathbf{a}$ & $3.893,00 \mathbf{a b}$ & $157,92 \mathbf{a}$ & $2.246,33 \mathbf{a}$ & $112,29 \mathbf{a}$ \\
Azevém & $1.338,16 \mathbf{a}$ & $23,86 \mathbf{a}$ & $2.427,66 \mathbf{b}$ & $32,50 \mathbf{c}$ & $2.649,99 \mathbf{a}$ & $32,78 \mathbf{a}$ \\
\hline CV \% & 41,60 & 51,92 & 29,77 & 29,86 & 36,77 & 59,41 \\
\hline DMS 5\% & $1.528,63$ & 50,99 & $2.527,4$ & 66,24 & $2.750,3$ & 112,50 \\
\hline
\end{tabular}

Médias seguidas da mesma letra na coluna não diferem estatisticamente entre si em nível de $5 \%$.

Em relação ao teor de $\mathrm{N}$ são observados, para o segundo corte, os maiores teores de $\mathrm{N}$ nas plantas de aveia preta, aveia branca, ervilhaca e centeio.

O N é um macronutriente essencial para as plantas e influi na absorção iônica, fotossíntese, respiração, síntese de carboidratos, multiplicação e diferenciação celular (MALAVOLTA, 1989). Isso justifica a maior quantidade de $\mathrm{N}$ no segundo, devido ao maior desenvolvimento das plantas. $\mathrm{O}$ perfilhamento e o crescimento vegetativo são estimulados pelo N.

Para o terceiro corte verificou-se a redução de matéria seca para aveia preta, centeio e ervilhaca o que poderia sugerir um aumento da competição dentro das espécies após o segundo corte.

\section{Considerações Finais}

No segundo corte, as maiores produções de matéria seca foram obtidas para o centeio, aveia branca e ervilhaca com $5.235 \mathrm{~kg} / \mathrm{ha}, 4.982 \mathrm{~kg} / \mathrm{ha}$ e $3.893 \mathrm{~kg} / \mathrm{ha}$, respectivamente, e não diferiram estatisticamente entre si.

Os teores mais elevados de nitrogênio, para o segundo corte, foram verificados para a ervilhaca, o centeio e a aveia preta que não apresentaram diferenças estatísticas entre si, com 157,9 kg/ ha 131,4 $\mathrm{kg} / \mathrm{ha}$ e 107,94 kg/ha, respectivamente.

Os resultados obtidos demonstraram que a utilização de plantas forrageiras como a ervilhaca, centeio e azevém, mesmo quando cultivadas em solos degradados, apresentam elevada produção. A utilização destas espécies em áreas degradadas deve ser monitorada com o objetivo de verificar também a contribuição destas na recuperação do solo.

\section{Agradecimentos}

Nossos agradecimentos aos Pesquisadores: Dr. Edilson Batista de Oliveira (EMBRAPA) e ao Dr. Daniel Perotto, do Instituto Agronômico do Paraná (IAPAR). 


\section{Referências}

BAGGIO, A. S. Recuperação de áreas degradadas. In: SIMPÓSIO NACIONAL, 1992, Curitiba: Fundação de Pesquisas Florestais do PR-FUPEF. Anais..., Curitiba: UFPR. 1992.

BISCAIA, R. C.; OSAKI, F. Levantamento de solos e aptidão agrícola a nível de propriedade rural. In: OSAKI, F. Microbacias: práticas de conservação de solos. Curitiba, PR: 1989. p. 193-198.

CORRÊA, A. R. Freqüência de geadas/ano no Estado do Paraná. IAPAR. In: Conservação do solos em sistemas de produção nas microbacias hidrográficas do Arenito Caiuá, Paraná. Londrina, 1990. p. 56.

FLOSS, E. L. A cultura da Aveia. Boletim Técnico da FAUPT- UFP , Passo Fundo, n. 1., p. 52. 1982.

INSTITUTO AGRONÔMICO DO PARANÁ (IAPAR). Cartas Climáticas do Estado do Paraná. Londrina: IAPAR. 1994. 49p.

LAWLOR, D. W. et al. Nitrate nutrition and temperature effects on wheat: a synthesis of plant growth and nitrogen uptake in relation to metabolic and physiological processes. Journal oF Experimental Botany, v. 39, p. 329-343, 1988.

MALAVOLTA, E. Avaliação do estado nutricional das plantas: princípios e aplicações/ Euripedes Malavolta e outros. Piracicaba: Associação Brasileira para Pesquisa da Potassa e do Fosfato, 1989.

MONTEIRO, A. L. G. et al. Forragicultura no

Paraná. Londrina, 1996. 291 p.
OLIVEIRA, I. P. de; et al Sistema Barreirão: utilização de fosfatagem na recuperação de pastagem degradada. Circular Técnica 31. Santo Antônio de Goiás: EMBRAPA - CNPAF. 1998. 51 p.

OSAKI, F.; BISCAIA, R. C. São José dos Pinhais, seus solos dominantes e suas produtividades. ENCONTRO PECUÁRIO - REGIÃO SUL/PRe no SEMINARIO TÉCNICO /IAPAR. In: Microbacias: práticas de conservação de solos. Curitiba, 1994.

OSAKI, F.; TRAAD DA SILVA, M. Pastagem em microbacias. 0 Estado do Paraná, 2000.

SÁ, J. P. G. Avaliação de forrageiras de inverno no Norte do Paraná. Informe da Pesquisa do IAPAR, Londrina, n. 54, p. 40, 1984.

SEITZ, R. A. Recuperação de áreas degradadas. In: - SIMPOSIO SUL-AMERICANO e SIMPÓSIO NACIONAL, 1992, Curitiba. Anais... Curitiba: Fundação de Pesquisas Florestais do PR FUPEF - 1992.

STEEL, R. G. D.; TORRIE, J. H. Principles and procedures of statistics with special reference to the biological sciences. New Y ork: MacGrawHill, 1960.

THOMAS, G. W. The relationship between organic matter content and exchangeable aluminum in acid soil. Soil Science Society of America Proceedings, Madison, v. 39, n. 3, p.591, 1975. 